\title{
Verification of Local Damage Progression during Post-Punching Shear Response
}

\author{
Ulaeto Nsikak William
}

1

Abstract - Analytical approaches are adopted for the modelling of post punching shear response of slab-column connections. These models emphasis on the load displacement response of connections for their validation. This is because load displacement relationships are easily obtained through experiment on post punching. Validation of local damage progression during post punching are often neglected, though they form the basis of compatibility relationships in analytical models. Hence, the need to verify analytical local damage progression in slab-column connections during post punching. A comparative assessment of analytical and numerical local damage progression was carried out in a view to ascertain the accuracy of existing analytical post-punching shear models. Assessments were carried out using six isolated slab test specimens available in literature. On comparison of different analytical models for modelling post punching shear, results showed similar response trends with percentage differences below $20 \%$ for local damage progression at most stages of the analysis. Analytical prediction of local damage progression compared well with results of numerical models. Average percentage differences between analytical and numerical values of local damage progression for both flexural and integrity reinforcement were below $15 \%$. Results show that local damage progression during post punching shear response of slab-column connections obtained analytically were satisfactory and analytical models were adequate for assessment of symmetric post punching shear response of reinforced concrete slab-column connections.

Index Terms - Reinforced concrete, Flat slabs, Post-punching shear, Local damage progression.

\section{INTRODUCTION}

\section{A. Background of the study}

Detailed assessment of structures during progressive collapse requires knowledge of the mechanisms developed and their interaction. Simple analytical assessment approaches are commonly adopted for such assessments since they are easy to apply, they do not require expensive hardware or software and they can be readily adapted for application in design codes. To simplify analytical approaches, equivalent static approaches are adopted, since the structural response could be dynamic. Possible changes in local and global failure modes due to dynamic effects are also considered (Hrynyk and Vecchio, 2014). This is important especially in flat slab structures where connections expected to fail in flexure could fail in punching shear due to dynamic influences.

Flat slab structures are reinforced concrete structures with slabs directly supported on columns. They are structural forms commonly adopted for residential and commercial buildings. For flat slab structures, mechanisms which could develop prior to and during progressive collapse include flexural action, punching shear action, post-punching shear action, and tensile membrane action. Some of these mechanisms are as defined in Figure 1. Post-punching shear action occurs after punching shear failure of the slab-column connection. Post-punching shear is characterized by the progressive spalling of concrete cover, breakage of concrete within the punching shear cone, breakage of concrete within the core of the slab (for cases with integrity reinforcement) and the membrane response of reinforcement connecting the punching shear cone to the slab.

\section{B. Statement of problem}

Analytical models exist for modelling of post-punching shear response of slab-column connections (Mirzaei, 2010; Habibi, Cook, and Mitchell, 2014; and Ulaeto and Sagaseta, 2020). Progressive spalling and breakage of concrete during post-punching is the basis for determination of the post-punching shear strength in these analytical models, prior to bond failure or rupture of integrity reinforcement. Different compatibility relationships are adopted by each model though they have all been validated through experiments on slab-column connections (Mirzaei, 2010; Habibi, Cook, and Mitchell, 2014; and Ulaeto and Sagaseta, 2020). Validations of analytical models available in literature were carried out based on the slab-column connection's global (load-displacement) responses. However, validations of the local damage progressions were not made to ascertain the accuracy of the compatibility assumptions with which load-displacement relationships were derived. This is because progression of local damage during post-punching shear response of slab-column connections is difficult to investigate by means of experiments alone.

\section{Aim and objectives of the study}

In this study, a comparative assessment of analytical and numerical local damage progressions in reinforced concrete slab-column connections during post-punching shear action was carried out in a view to ascertain the accuracy of existing analytical post-punching shear models. Objectives of the study included;

i. assess existing analytical local damage progression models using post punching shear models available in literature, identify their differences and compare results obtained from use of these models.

ii. assess numerical local damage progression models and adopt numerical models for verification of existing analytical models.

iii. Good agreement between analytical and numerical results is needed to ascertain the accuracy of assumptions adopted in existing analytical models. Of importance amongst these assumptions is the 
compatibility relationships. Compatibility relationships differ amongst various analytical models.

a)

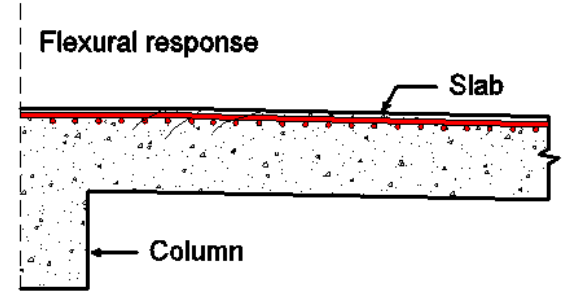

b)

Punching shear response

c)

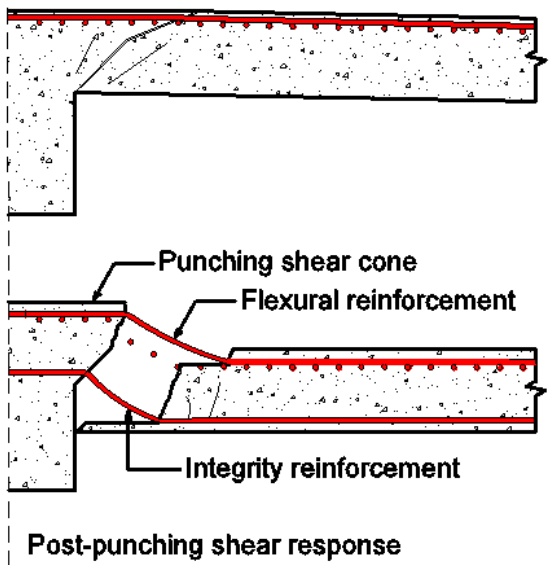

d)

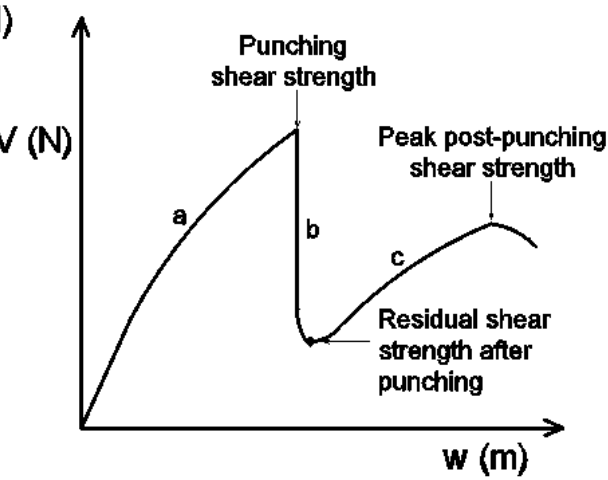

Figure 1: Flexural, punching shear and post-punching shear response of a slab-column connection.

\section{LITERATURE REVIEW}

\section{A. Tests on response of slab-column connections}

Tests on the response of slab-column connections available in literature primarily cover tests on the punching shear response with and without punching shear reinforcement (Muttoni, 2008, and Loo and Guan, 1997). Punching shear tests have also covered cases of non-symmetrical punching of flat slabs (Sagaseta et al., 2011), influence of edge restraints on punching shear (Taylor et al., 2009), influence of compressive membrane action (Belletti, Vitulli and Walvaren, 2014), effect of low reinforcement ratio (Guandalini, Burdet and Muttoni, 2009) and type and quantity of punching shear reinforcement provided (Lips, Ruiz and Muttoni, 2012).

Tests covering post-punching shear responses of typical slab-column connections also provide information on the punching shear strength of the slab-column connections.
Though several researches have been carried out on punching shear, fewer works are available on post-punching shear response. Melo and Regan (1998) carried out tests which consisted of 3 series. Test series 1 consisted of typical slab-column connections. Slab specimens were $2.5 \mathrm{~m}$ square and $75 \mathrm{~mm}$ thick. Tests comprised of specimens with and without integrity reinforcement. Results of tests showed that specimens with bottom bars passing through the column and anchored in the slab to either side provided higher resistance in post-punching than specimens without.

Ruiz et al. (2013) tested 20 slab-column specimens in four test series. Specimens were 1500 x $1500 \mathrm{~mm}$ and $125 \mathrm{~mm}$ thick. They were pin supported on eight steel plates, positioned at a radius of $747 \mathrm{~mm}$ from the centre of the slab. Of the four test-series considered, Test series 1 contained no integrity reinforcement while Test series 2 contained integrity reinforcement. Test series 3 contained bent-up bars and Test series 4 contained short-length flexural reinforcement. Slab characteristics for specimens PM2, PM4, PM9 and PM12 are as highlighted in Table I. Parameters presented in Table I are as described in Figure 2. Test results showed that large deformations were required for the activation of integrity reinforcement in post punching.

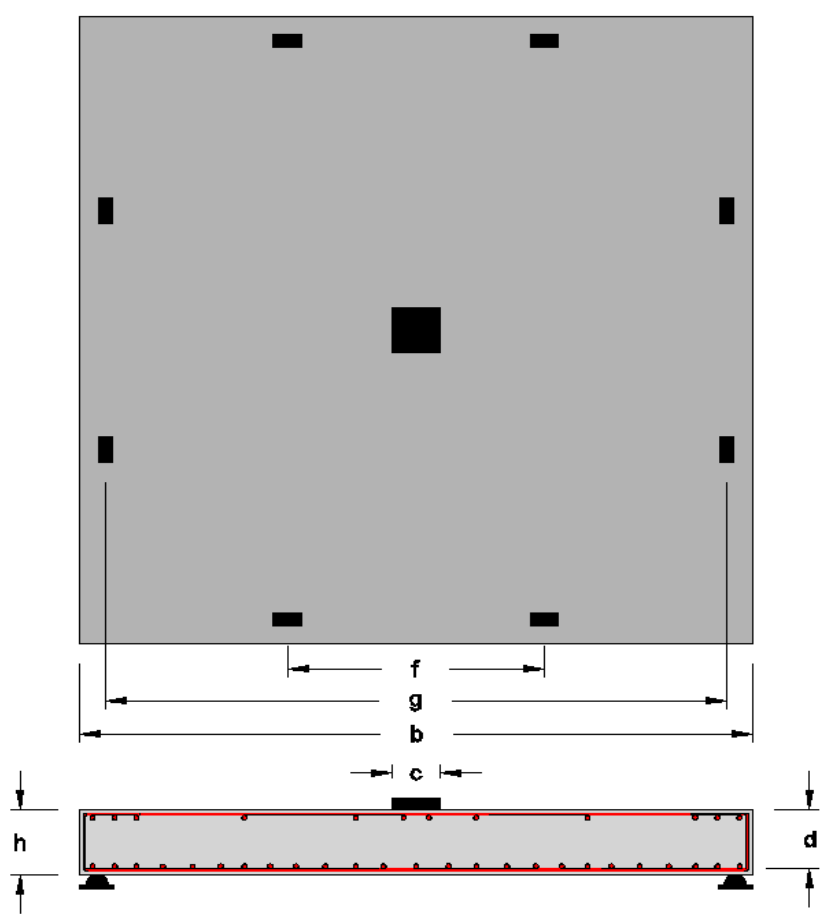

Figure 2: Characteristics of typical slab-column test specimen.

Habibi, Redl, Egberts, Cook, and Mitchell (2012) reported on tests carried out on slab-column specimens to assess their post-punching response. This report included test specimen SS and RS. Test specimen SS and RS were both 2300 x 2300 $\mathrm{mm}$ with thicknesses of $200 \mathrm{~mm}$. The central rectangular column stubs for specimen SS and RS were 225 x $225 \mathrm{~mm}$ and $180 \times 270 \mathrm{~mm}$ respectively. Slab specimens were supported at the column stubs and loads applied at 8 points along the elastic line of contraflexure of the slab. Characteristics of slab specimen SS and RS are also highlighted in Table I. From test results Habibi, Redl, Egberts, Cook, and Mitchell (2012) concluded that flexural reinforcement provided limited post-punching shear 
Table I: Characteristics of slab-column test specimens obtained from literature

\begin{tabular}{lllllll}
\hline Parameter & PM2 & PM4 & PM9 & PM12 & SS & RS \\
\hline$b(m)$ & 1.5 & 1.5 & 1.5 & 1.5 & 2.3 & 2.3 \\
$g(m)$ & 1.38 & 1.38 & 1.38 & 1.38 & 2.0 & 2.0 \\
$f(m)$ & 0.575 & 0.575 & 0.575 & 0.575 & 0.75 & 0.75 \\
$c(m)$ & 0.13 & 0.13 & 0.13 & 0.13 & 0.225 & $0.18 / 0$. \\
& & & & & & 27 \\
$h(m)$ & 0.125 & 0.125 & 0.125 & 0.125 & 0.2 & 0.2 \\
$d(m)$ & 0.102 & 0.102 & 0.102 & 0.102 & 0.16 & 0.2 \\
$f_{c}(\mathrm{MPa})$ & 36.5 & 36.8 & 31 & 32.4 & 26 & 0.16 \\
$f_{c t}(\mathrm{MPa})$ & 2.8 & 3.0 & 3.0 & 2.6 & $3.35 *$ & $3.16 *$ \\
$\rho(\%)$ & 0.49 & 1.41 & 0.82 & 0.82 & & $* *$ \\
& & & & & $*$ & \\
$f_{\text {sy }}(\mathrm{MPa})$ & 601 & 601 & 601 & 601 & 420 & 420 \\
$f_{\text {su }}(\mathrm{MPa})$ & 664 & 664 & 664 & 664 & 723 & 723 \\
$f_{\text {sy.int. }}(\mathrm{MPa})$ & - & - & 616 & 527 & 420 & $* * *$ \\
$f_{\text {su.int. }}(\mathrm{MPa})$ & - & - & 680 & 629 & 723 & $* * *$ \\
$\Phi_{\text {int. }}(\mathrm{m})$ & - & - & 0.008 & 0.014 & 0.016 & $* * *$ \\
\hline
\end{tabular}

* Splitting tensile strength

$* * 16 \mathrm{~mm} \Phi$ bars provided at a spacing of $160 \mathrm{~mm}$ within $0.64 \mathrm{~m}$ from the column centre and at $200 \mathrm{~mm}$ beyond

*** 2\# $11.3 \mathrm{~mm} \phi$ bars provided at the short side of connection and $3 \# 16 \mathrm{~mm} \phi$ bars provided at the long side

Sources:

PM2, PM4, PM9 and PM12: Ruiz, Mirzaei and Muttoni (2013)

SS and RS: Habibi et al. (2012)

B. Numerical models for assessment of slab-column connections response

resistance relative to integrity reinforcement. Habibi, Redl, Egberts, Cook, and Mitchell (2012) also concluded that increasing the thickness of a slab increased the post punching shear resistance of slab-column connections.

Numerical procedures have been developed by Keyvani, Sasani, and Mirzaei (2014), Liu, Tian, and Orton (2015), Olmati, Sagaseta, Cormie, and Jones (2017) and Ulaeto and Sagaseta (2017) for the assessment of response of flat slab structures after the loss of an internal column. Adequate modelling of slab-column connection is vital for the accuracy of such assessments.

Keyvani et al. (2014) adopted connections with no punching shear reinforcement provided. Punching shear cones were modelled independently with each failure surface of the cone inclined at an angle of $45^{\circ}$ the horizontal. Punching shear cones were attached to adjoining slabs using eight three-dimensional cartesian cardan connectors elements. After punching, cartesian-cardan connector elements were considered in post-punching by assigning concrete breakage and spalling strengths calculated analytically. Failure of rebar-concrete connectors during post-punching, simulated progression of concrete breakage and spalling. Model proposed by Keyvani et al. (2014) does not explicitly consider interaction between concrete and reinforcement in post-punching. Such interactions maybe influenced by factors such as asymmetric deformation.
Liu et al. (2015) investigated the response of a three-story flat slab building after the sudden removal of interior and exterior columns. This investigation was carried out numerically using shell (two dimensional) elements. Slab-column connections were modelled at each column side using two connector beam (one dimensional) elements. Load deformation and failure characteristics of the connector beam elements were obtained from the load-rotation and failure criterion relationships of the Critical Shear Crack Theory (CSCT) (Muttoni, 2008). Though compression reinforcement was provided and partially embedded into the column, its contribution and that of flexural reinforcement in post-punching were not considered in the analysis.

Olmati et al. (2017) developed a numerical model for an existing four-story flat slab office building described in The Concrete Society (2007). Reinforced concrete slabs were modelled using layered shell elements. At the connections, shell elements were directly connected to the column. Hence, connection numerical models simulated neither punching shear nor post-punching shear failure. Checks for punching shear failure of each connection were carried out after numerical analysis. Load rotation responses of slab around each connection were extracted and analysed with the calculated failure criteria (Muttoni, 2008). This numerical approach adopted by Olmati et al. (2017) does not take into consideration the contribution of post-punching shear action.

Ulaeto and Sagaseta (2017) developed a three-dimensional numerical model which adequately predicted the response of slab-column connections in punching and post-punching. An explicit Finite Element (FE) solver was adopted due to the 
high material and geometric nonlinearities associated with post-punching response. Concrete was modelled using 8 noded hexahedron solid (three dimensional) elements and reinforcement modelled using the Hughes-Liu beam (one dimensional) elements. The Winfrith-Concrete constitutive material model (Broadhouse and Neilson, 1987) was used to model concrete material properties and the Plastic-Kinematic constitutive material model adopted for steel reinforcement. Loading of slab models were carried out by gradually increasing slab displacement at loading points as observed in tests (Ruiz et al., 2013 and Habibi et al., 2012). Slab displacement was controlled at 0.0006 metres per second. Good agreement was generally observed between the global numerical response with those of tests. Percentage differences between test and numerical punching shear strengths range from 0.03 to 2 percent. For shear strength after punching and peak post-punching shear strength, differences ranged from 0.03 to 21 and 0.03 to 3 percent respectively.

\section{Analytical models for assessment of slab-column connection response}

Melo and Regan (1998) developed Equations 1 to 4 for determination of the response of bottom bars in slab-column connections. These were based on analytical break out relationships for bars embedded in concrete (ACI, 1978 and ACI, 2001). Equation 1 represents the pull-out load for a single bar and Equation 2 represents the break out load for each pair.

$$
\begin{gathered}
V_{R, p p}=0.33 \sqrt{f_{c}^{\prime}} \pi \frac{d_{r e s}^{2}}{2} \\
V_{R \cdot p p}=0.33 \sqrt{f_{c}^{\prime}} \pi \frac{d_{r e s}^{2}}{2}-A_{1}
\end{gathered}
$$

Where, $V_{R, p p}$ is the break out load for each pair, $f_{c}^{\prime}$ is the compressive strength of concrete, $\mathrm{d}_{\text {res }}$ is the depth of concrete above steel bars and $A_{1}$ is defined by the relationship,

$$
\begin{gathered}
A_{1}=\frac{\Delta}{360} \pi d_{r e s}^{2}-\frac{s}{4} d_{\text {res }} \sin \Delta \\
\text { Where, } \Delta=\arccos \left(\frac{s}{2 d_{\text {res }}}\right) \\
V_{R \text { pp.rupt }}=0.44 \sum A_{s} f_{y}
\end{gathered}
$$

Equation 5 was developed by Melo and Regan (1998) to limit the post-punching shear strength due to the possible rupture of bottom reinforcement.

Mirzaei (2010), Habibi, Cook and Mitchell (2014) and Ulaeto and Sagaseta (2020) developed analytical models which predicted the progressive destruction of concrete around flexural and compression reinforcement during post-punching. Models developed by Mirzaei (2010) and Habibi, Cook and Mitchell (2014) were also based on the analytical break out relationship for bars embedded in concrete (ACI, 1978 and ACI, 2001). While Mirzaei (2010) and Ulaeto and Sagaseta (2020) considered increasing local damage progression in directions towards and away from the punching shear cone, Habibi, Cook and Mitchell (2014) only considered increasing local damage progression away from the punching shear cone for integrity reinforcement. For flexural reinforcement, Habibi, Cook and Mitchell (2014) assumed equal progression in both directions all through the analysis. Ulaeto and Sagaseta (2020) extended these analytical assessments to cases of asymmetric post-punching shear responses for application to progressive collapse of flat slab structures. In these analytical models slab displacement was used as the basis for the summation of break-out forces calculated for reinforcement. This was because slab compatibility relationships related the progression of concrete breakage ( $p$ and $q$ ) to the overall slab displacement, $w$.

Tests on both symmetric and asymmetric post-punching response of slab-column connections are few. Available data relates post-punching shear strength to slab displacement. Information available on slab damage progression during post punching is limited. This is due to difficulty in measurement of these data. However, information on the local damage progression during post punching can be obtained numerically (Ulaeto, Ekop and Antia, 2020).

\section{MATERIALS AND METHODS}

\section{A. Analytical modelling}

Analytical model presented by Ulaeto and Sagaseta (2020) was adopted in this research due to the ease of generation of parameters required in its application. Slab-column connection relationships for this analytical model were developed based on the failure mode presented in Figure 3. Local damage progressions are defined by $p$ (concrete breakage towards the punching shear cone) and $q$ (concrete breakage away from the punching shear cone). Break out strength at a level of progression $p$ or $q$ is obtained from the relationship;

$$
V_{\text {con. }}=A_{\text {ch }} \cdot f_{\text {ct.eff }}
$$

Where for two or more bars with $s<2 d_{\text {res }}$ the area of horizontal projection of the breakout cone $\left(A_{c h}\right)$ is given by,

$$
\begin{aligned}
& A_{c h}=\left\{\left[\Delta+\frac{n}{2}(\pi-2 \Delta)\right] d_{r e s}^{2} \cot ^{2} \gamma+\frac{n-1}{2} s d_{r e s} \cot \gamma \sin \Delta\right\} \\
& \Delta=\arccos \left(\frac{s}{2 d_{r e s} \cot \gamma}\right) \\
& d_{r e s}=\left\{\begin{array}{cc}
p_{i} \cdot \tan \theta_{1} & : 0 \leq d_{\text {res }} \leq \frac{d}{3} \\
{\left[p_{i}-\frac{d}{3} \cot \theta_{1}\right] \tan \theta_{2}+\frac{d}{3}} & : \frac{d}{3} \leq d_{r e s} \leq d
\end{array}\right. \\
& \text { and; } \quad d_{\text {res.int. }}=\left\{\begin{array}{cl}
q_{\text {int } . i} \tan \theta_{2} & : 0 \leq d_{\text {res.int }} \leq\left(\frac{2 d}{3}-g\right) \\
{\left[q_{\text {int } . i}-\left(\frac{2}{3} d-g\right) \cot \theta_{2}\right] \tan \theta_{1}+\left(\frac{2 d}{3}-g\right)} & :\left(\frac{2 d}{3}-g\right) \leq d_{\text {res.int }}<(d-g) \\
d-g & ; d_{\text {res.int }}=(d-g)
\end{array}\right.
\end{aligned}
$$




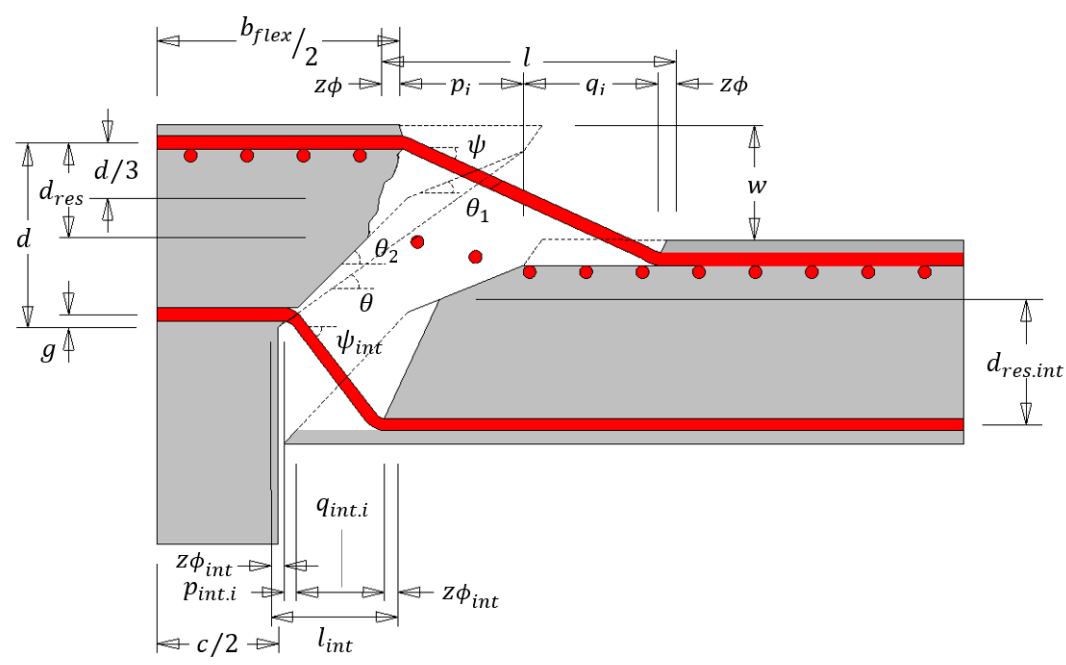

Figure 3: Geometric assumptions in proposed analytical modelling of post-punching shear mechanism (Ulaeto and Sagaseta 2020)

Where $\sum V_{\text {con }}$ is less than the shear load at the connection, $p$ or $q$ increases. Increases in $p$ and $q$ increases $d_{\text {res.int. }}$ and $V_{\text {con. }}$. The maximum depth, $d_{\text {resint } \max }=d-g$, is reached if the total resistance provided through post-punching is less than the shear load at the connection.

Compatibility relationships related the force in the reinforcement, $f_{\text {s.mem. }}$, to its displacement, $w_{\text {mem. }}$. Assuming all the shear at the later stages of the post-punching response is carried through membrane action,

$$
f_{\text {s.mem. }}=\frac{4 V}{n_{\text {break }} \pi \Phi^{2} \sin \psi_{\text {mem. }}}
$$

where, $\psi_{\text {memx }}$ is the rotation of a reinforcement during the membrane stage and is as described in Figure 3 for both flexural and integrity reinforcement. At a horizontal distance from the column centre, reinforcement displacement was assumed to be equal to that of the slab, $w$. Reinforcement displacement was obtained using the relationship;

$$
\begin{aligned}
& \quad w_{\text {mem. }}=l \text { tan } \psi_{\text {mem. }} . \\
& \text { where, } \quad l=z \phi+p i+q i+z \phi
\end{aligned}
$$

The parameter $\phi$ is the diameter of reinforcing steel bar and $z$ is a factor defining the curvature influenced zone. Values of 6 and 4 were adopted by Ulaeto and Sagaseta (2020) for $z$ for loads up to yielding and fracture respectively.

\section{B. Numerical modelling}

Numerical models were developed using the LSDYNA finite element (FE) solver. Models were three-dimensional, incorporating 8 noded hexahedron solid (three dimensional) elements and reinforcement modelled using the Hughes-Liu beam (one dimensional) elements. They were developed as described in Ulaeto and Sagaseta (2017). An explicit FE solver was adopted due to the high material and geometric nonlinearities associated with post-punching response. Concrete material properties were modelled using the Winfrith-Concrete constitutive material model (Broadhouse and Neilson, 1987) and the Plastic-Kinematic constitutive material model was adopted for steel reinforcement. Bond between concrete and reinforcement was modelled using the "constrained beam in solid" model. Slab models were loaded gradually by increasing slab displacement at loading points. This was as adopted in experiments by Ruiz, Mirzaei and Muttoni (2013) and Habibi et al., (2012). Slab displacements during loading were controlled at 0.0006 metres per second.

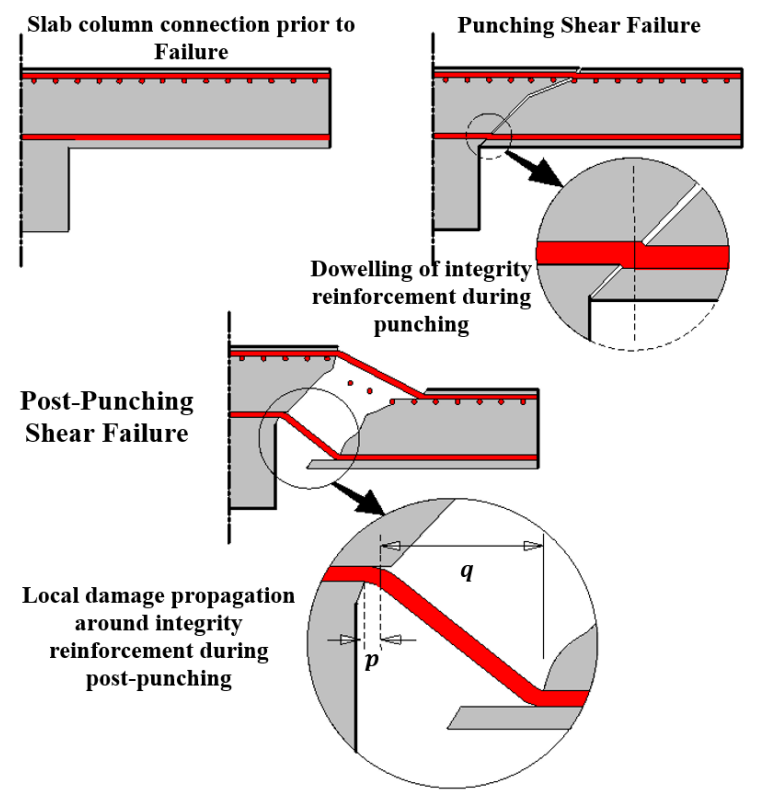

Figure 4: Consideration of local damage progression using reinforcement deformation profile

Local damage progression was observed using reinforcement deformation profile. To obtain the reinforcement deformation profiles, sections were cut through the slab models along the axis of the reinforcement being considered. Only the flexural reinforcement running closest to the support was considered. Integrity reinforcement was also considered as it is detailed to pass through the column core in both orthogonal directions. Prior to punching shear failure, the connection responds in flexure. The reinforcement was expected to have a constant curvature close to the support. At punching shear failure, a small kink due to dowelling action develops at the point the reinforcement crosses the critical punching shear crack. This kink is as depicted in Figure 4. Development of 
post-punching shear leads to the spread of the kink both towards and away from the punching shear cone. This is also as shown in Figure 4. The distance of the point of initial kink at punching to its end towards the punching shear cone and away from it provided information on the progression of concrete breakage and spalling respectively.

\section{PRESENTATION AND DisCUSSION OF RESUlTS}

A. Local damage progression based on existing analytical post punching models

Local damage progression as considered by analytical models in literature differ in their assumptions. These differences have been highlighted in a literature review section. Results of comparisons of local damage progression obtained using post punching shear models proposed by Habibi, Cook and Mitchell (2014) and Ulaeto and Sagaseta (2020) are as shown in Figure 5.

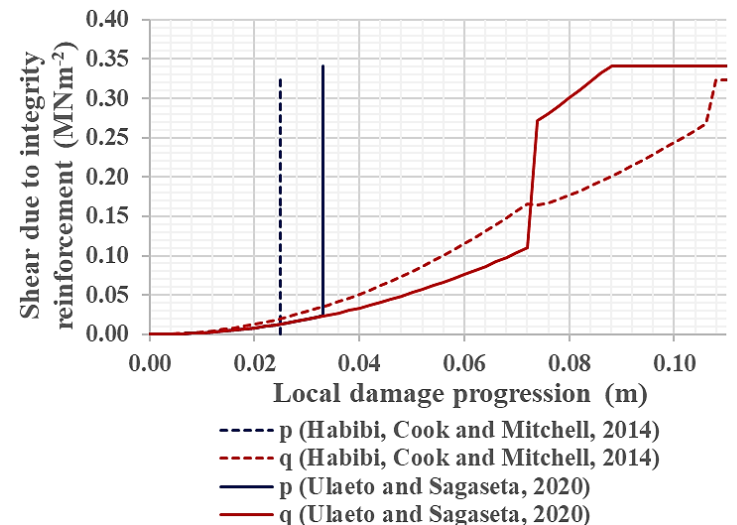

(a)

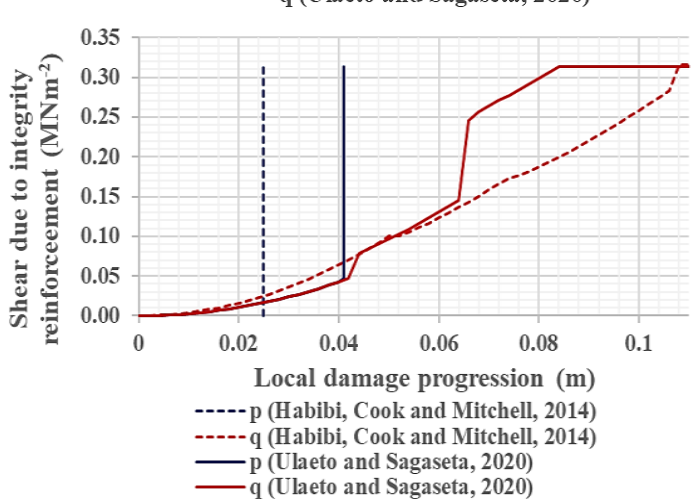

(b) - q (Ulaeto and Sagaseta, 2020)

Figure 5: Relationship between analytically derived post punching shear and local damage progression of integrity reinforcement (a) Slab test specimen SS and (b) Slab test specimen RS.

Percentage difference for the maximum local damage progression towards the punching shear cone, $p$, between models from Ulaeto and Sagaseta (2020) and Habibi, Cook and Mitchell (2014) gave a value of $20 \%$ at a post punching shear resistance of $150 \mathrm{kNm}^{-2}$, for slab model SS. A $7 \%$ difference was obtained for local damage progression away from the punching shear cone, $q$, also at a post punching shear resistance of $150 \mathrm{kNm}^{-2}$, for slab model SS. The parameter $p$ from Ulaeto and Sagaseta's model showed progressions equal to $q$ up to the column face where no further increase in progression was observed. For Habibi, Cook and Mitchell's model no progression was observed for $p$. These observations were due to assumptions adopted in the various models. Ulaeto and Sagaseta (2020) considered increasing local damage progression in both the $p$ and $q$ directions while Habibi, Cook and Mitchell (2014) only considered increasing local damage progression in the $q$ direction for integrity reinforcement. Figure 5 show responses for local damage progression in the direction away from the punching shear cone, $q$.

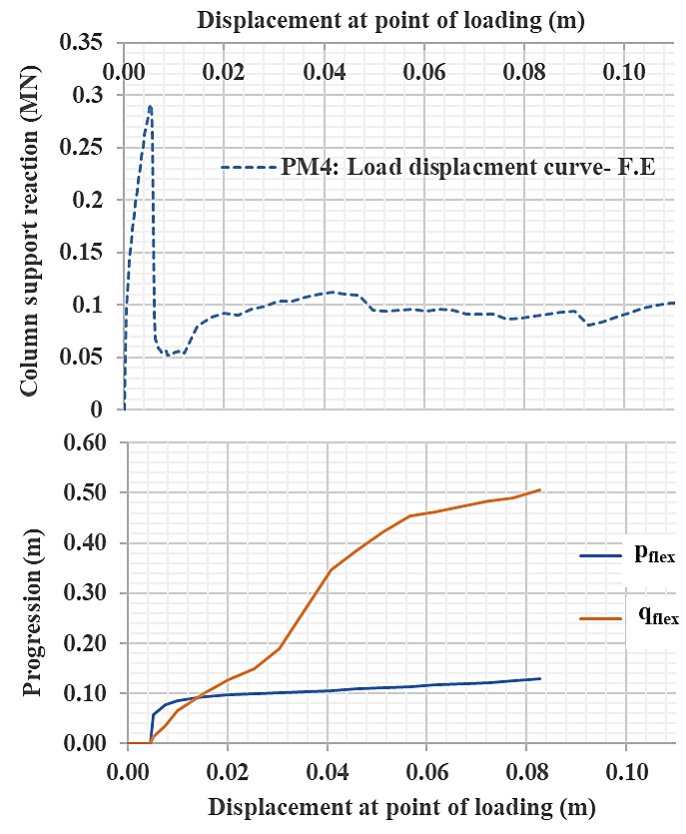

(a)
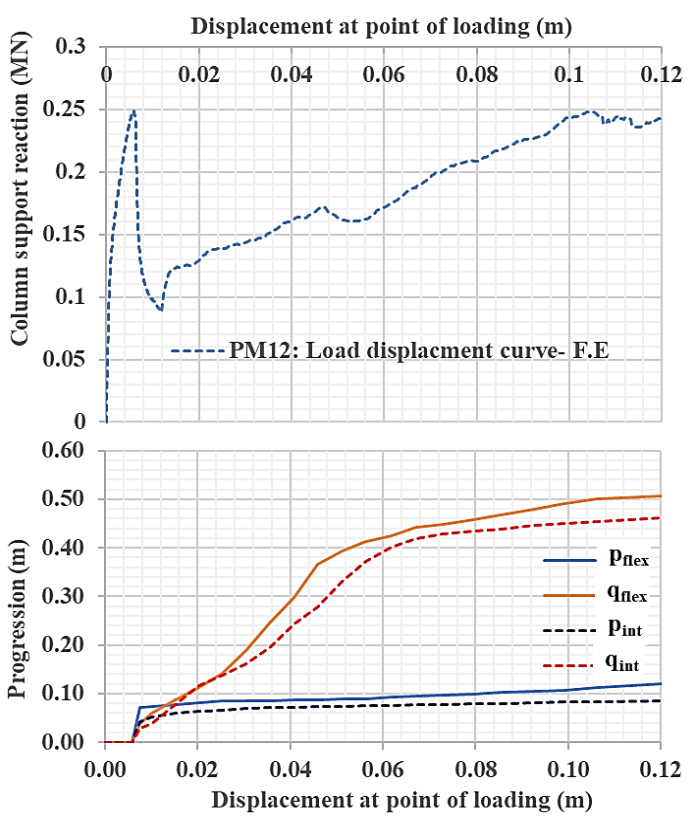

Figure 6: Comparison of $p$ and $q$ for flexural and integrity reinforcement with slab-column connection global response

Local damage progression results obtained using the model by Ulaeto and Sagaseta (2020) was observed to be more sensitive to transitions in the angles of the post punching shear failure surface. This failure surface is as presented in Figure 3. However, results from both models showed similar trends. Ulaeto and Sagaseta's model attained peak post punching shear strength at smaller values of $q$. This is believed to be due to the adoption of a steeper average punching shear failure surface $\left(35^{\circ}\right)$ relative to that adopted by Habibi, Cook and Mitchell (2014) which had an average angle of $29^{\circ}$. 

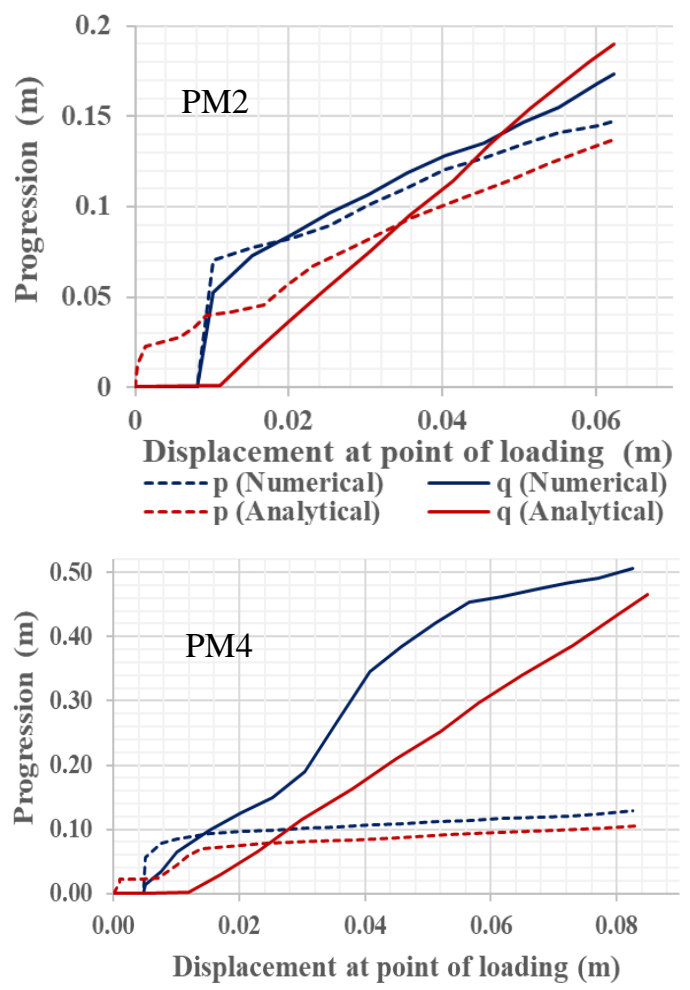

(b)

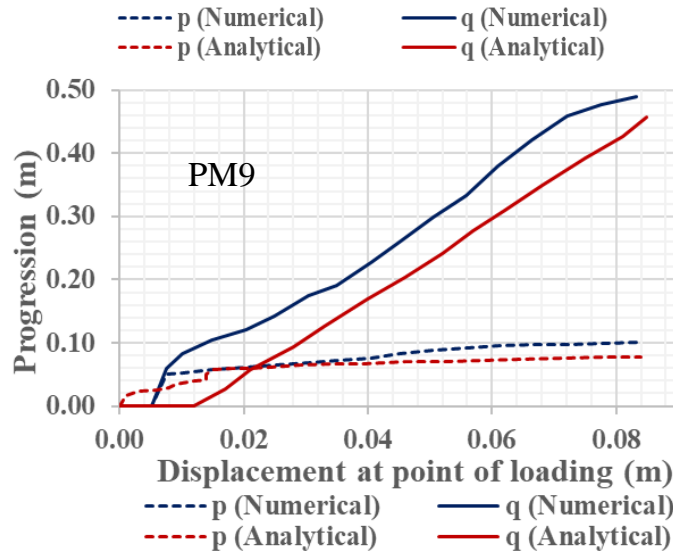

(c)

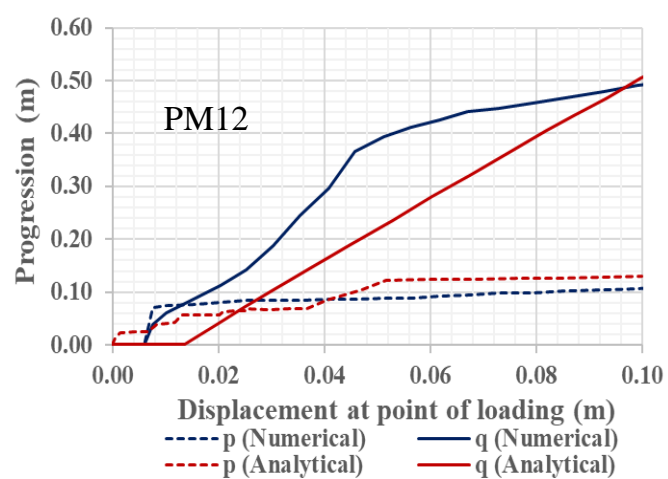

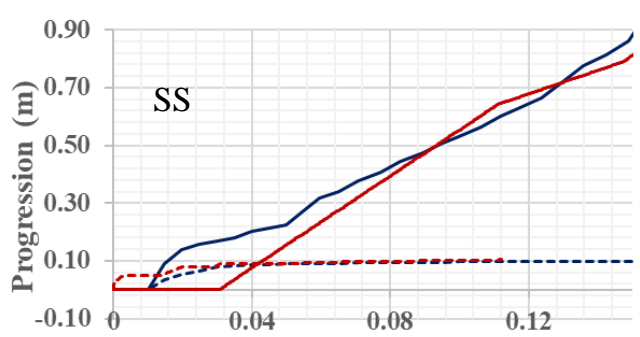

- D p (Numerical) $-q$ (Numerical)

(e)

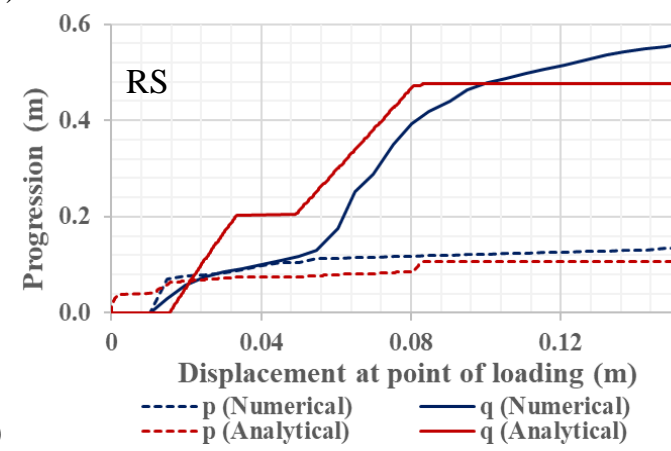

Figure 7: Local failure progression - displacement relationships for flexural reinforcement in slab-column test specimens (a) PM2, (b) PM4 (c) PM9, (d) PM12, (e) SS, and (f) $\mathrm{RS}$
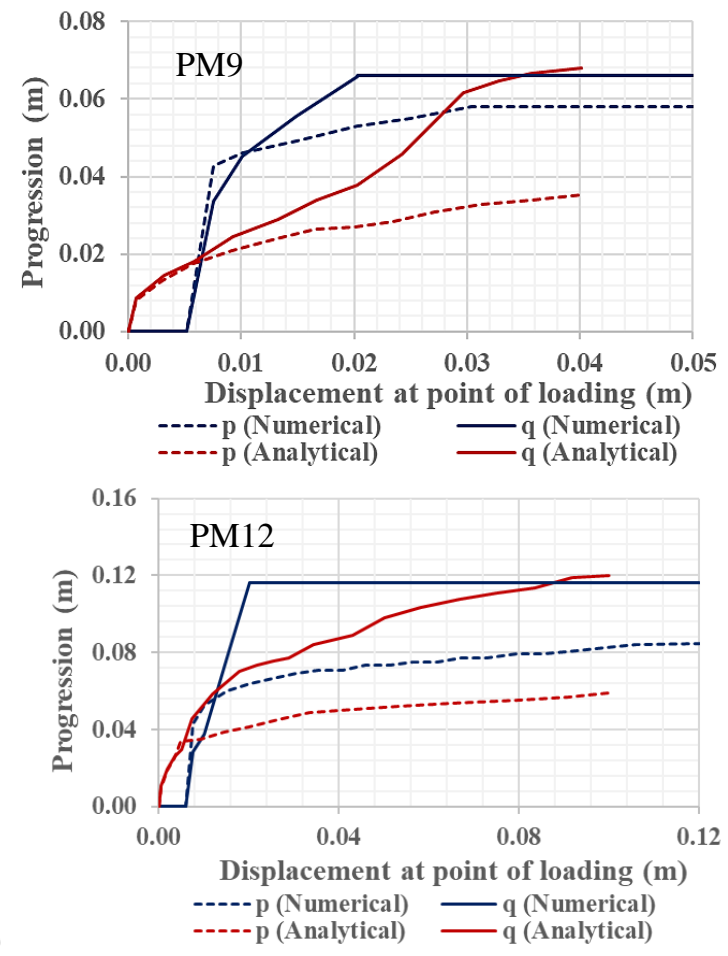

Figure 8: Local failure progression - displacement relationships for integrity reinforcement in slab-column test specimens (a) PM9 and (b) PM12

B. Numerical modelling of local damage progression during post punching

Local damage progression during post punching shear response of slab-column connections was assessed numerically. Results of local damage progression in relation to the load displacement relationship for slab-column specimens PM4 and PM12 are as shown in Figure 6.

Numerical results showed that local damage progression remained zero before punching shear failure of slab-column 
connections. Punching shear failure is defined by the sudden drop in the load carrying capacity of the connection. Increases in the parameters $p$ and $q$ were observed after punching shear failure. This showed the activation of post punching shear resistance. These increases in the value of $p$ and $q$ continued until either the reinforcement failed in bond anchorage, it ruptured, or the local damage progression extended to the slab edges or column faces.

C. Verification of analytical local damage progression models using numerical models

Analytical data were obtained for local damage progression during post punching shear. These data were compared to those obtained numerically to verify accuracy of assumptions adopted for local damage progression. These results are as shown in Figure 7 for flexural reinforcement and Figure 8 for integrity reinforcement.

\section{Flexural reinforcement}

Analytical results for flexural reinforcement agreed with those obtained from finite element modelling. Average differences between values of $p$ and $q$ at peak post punching shear strength were below $15 \%$. Though, local progression values for $p$ increased from the start of the analysis, values for $q$ increased when the post punching shear resistance of the embedded reinforcement outside the punching shear cone was less than that within the cone. These differed from the numerical models, where sudden increases in $p$ and $q$ commenced at displacements which were equivalent to those at which punching shear failure occurred. These signified the activation of post punching shear in the numerical models.

Results also showed that at the initial displacements numerical results for local damage progression were higher than those obtained analytically. This was true for both $p$ and $q$ and was attributed to dynamic effects developed in the slab-column during the change in slabs' kinematics, from a punching shear deformation shape to a post punching deformation shape. Dynamic effect during static post punching shear tests have been reported by Mirzaei (2010). This is also confirmed in Figure 6, where the sudden drop in punching shear strength corresponds to a sudden initiation of post punching shear response. These dynamic effects were not taken into consideration in analytical models.

For comparison with results of analytical models, numerical results for integrity reinforcement were only considered where significant axial deformation were not observed. Hence, local damage progressions for integrity reinforcement were not considered after significant yielding or after the bond failure of integrity reinforcement. This was because when stresses in integrity reinforcement were close to or above the yield stress as shown in Figure 9, significant axial deformation of the reinforcement influenced measured numerical values of $p$ and $q$. This allowed for good comparison of results since, the influence of axial deformations of integrity reinforcement during post punching were not considered in analytical models for determination of $p$ and $q$.

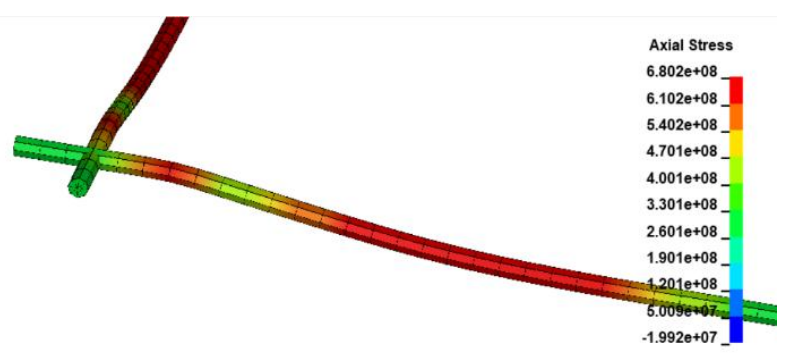

Figure 9: Axial stresses $\left(\mathrm{Nm}^{-2}\right)$ in integrity reinforcement of finite element model PM9 on reaching its fracture stress.

\section{CONCLUSION AND RECOMMENDATIONS}

This study carried out assessments of analytical and numerical local damage progression during post punching shear in slab-column connections. This was to ascertain the accuracy of existing analytical post punching shear models. Analytical approaches for modelling post punching responses which are available in literature were adopted. Local damage progression obtained using two of these approaches (Habibi, Cook and Mitchell, 2014; and Ulaeto and Sagaseta, 2020) were compared. Analytical post punching shear model proposed by Ulaeto and Sagaseta (2020) was adopted and local damage progression during post punching shear was calculated. Analytical results of local damage progression were verified using results of numerical models developed.

There was good agreement between results of local damage progression, calculated from analytical models obtained from literature. Though the model proposed by Ulaeto and Sagaseta, (2020) attained peak post punching shear strength at lower local progression lengths than that of Habibi, Cook and Mitchell (2014), this differences were not significant. Good agreement was also observed in local damage progression between analytical and numerical models. Sudden increases in local damage progressions observed at the initial stages of numerical analyses were attributed to dynamic effects which occurred during punching shear failure.

Analyses of research results showed that local damage progression during post punching shear response of slab-column connections obtained analytically were adequate. Compatibility assumptions satisfied both load-displacement and local damage progression displacement results. Hence, the analytical model assessed was adequate for assessment of symmetric post punching shear response of reinforced concrete slab-column connections.

\section{REFERENCES}

[1] T. Hrynyk, and F. Vecchio, "Behavior of steel fiber-reinforced concrete slabs under impact load", ACI Structural Journal (2014), 111(5), pp. 1213-1224.

[2] Y. Mirzaei, Post-Punching Behavior of Reinforced Concrete Slabs. PhD Thesis (2010), Ecole Polytechnique Federal De Lausanne.

[3] F. Habibi, W. Cook, and D, Mitchell, "Predicting Post-Punching Shear Response of Slab-Column Connections", ACI Structural Journal (2014), 111(1), pp. 123-134.

[4] N. Ulaeto, and J. Sagaseta, "A post-punching shear model for column-slab connections for progressive collapse analyses", Magazine of concrete research, published online before print (2020).

[5] A. Muttoni, "Punching Shear Strength of Reinforced Concrete Slabs", ACI Structural Journal (2008), 105, pp. 440-450. 
[6] Y. Loo, and H. Guan, "Cracking and punhing shear failure analysis of RC flat plates", Journal of Structural Engineering (1997), 123(10), pp. $1321-1330$.

[7] J. Sagaseta, A. Muttoni, M. Ruiz and L. Tassinari "Non-axis-symmetrical punching shear around internal columns of RC slabs without transverse reinforcement", Magazine of concrete research (2011), 63(6), pp. 441-457.

[8] J. Alam, K. Amanat and S. Seraj, "Experimental investigation of edge restraint on punching shear behaviour of RC slabs", The IES Journal Part A : Civil and Structural Engineering (2009), 2(1) pp. 37-41.

[9] B. Belletti, F. Vitulli, and J. Walvaren "Compressive membrane action in confined RC and SFRC circular slabs". Computational modelling of concrete structures, (2014), pp. 807-818.

[10] S. Guandalini, O. Burdet, O and A. Muttoni "Punching Tests of Slabs with Low Reinforcement Ratios", ACI Structural Journal (2009), (106), pp. 87-95.

[11] S. Lips, M. Ruiz, and A. Muttoni, "'Experimental Investigation on Punching Strength and Deformation Capacity of Shear-Reinforced Slabs", ACI Structural Journal (2012), 109, pp. 889-900.

[12] G. Melo, and P. Regan, "Post-punching resistance of connections between flat slabs and interior columns", Magazine of concrete research (1998), 50(4), pp. 319-327.

[13] Ruiz, F., Mirzaei, Y. and Muttoni, A. (2013) 'Post-Punching Behavior of Flat Slabs', ACI Structural Journal, 110(5), pp. 801-812.

[14] F. Habibi, E. Redl, M Egberts, W. Cook and D. Mitchell, "Assessment of CSA A23.3 structural integrity requirements for two-way slabs.(Report)", Canadian Journal of Civil Engineering, (2012), 39(4).

[15] L. Keyvani, M. Sasani, and Y. Mirzaei, "Compressive membrane action in progressive collapse resistance of RC flat plates", Engineering Structures (2014), 59, pp. 554-564.

[16] J. Liu, Y. Tian and S. Orton, "Resistance of Flat-Plate Buildings against Progressive Collapse. II: System Response", Journal of Structural Engineering (2015), 141(12).

[17] P. Olmati, J. Sagaseta, D. Cormie and A. Jones 'Simplified reliability analysis of punching in reinforced concrete flat slab buildings under accidental actions', Engineering Structures (2017), 130, pp. 83-98.

[18] N. Ulaeto and J. Sagaseta, "Numerical modelling of symmetric and asymmetric punching and post-punching shear responses of RC flat slabs", The 11th European LS-DYNA Conference, (2017) Salzburg.

[19] The Concrete Society, "Technical Report No 64- Guide to the design and construction of reinforced concrete flat slabs". The Concrete Society (2007).

[20] B. Broadhouse, and A. Neilson, "Modelling reinforced concrete structures in DYNA3D", AEEW-M2465, (1987).

[21] American Concrete Institute ACI 349-78 (1978), Code requirements for nuclear safety related concrete structures, Chicago.

[22] American Concrete Institute ACI 349-01 (2001) Code requirements for nuclear safety related concrete structures, Chicago.

[23] N. Ulaeto, I. Ekop, and M, Antia, "Local damage progression in slab-column connections during post-punching", Journal of Environmental Design (2020), 15(1).

\section{LIST OF SYMBOLS}

Latin upper case letters

$A_{c h} \quad$ Area of the horizontal projection of the conical surface

$A_{g} \quad$ Required area of steel reinforcement

$A_{\text {sint }}$ Required area of integrity reinforcement for symmetric cases

$E_{s} \quad$ Modulus of elasticity of flexural steel

$E_{s h} \quad$ Tangential modulus at initial strain hardening

$I_{g} \quad$ Second moment of area of steel rebar

$V_{\text {con break }}$ Shear strength developed from breaking of concrete within the punching shear cone

$V_{\text {consppall }}$ Shear strength developed from breakage of concrete outside the punching shear cone

$V_{R} \quad$ Shear strength

$V_{R e}$ Punching shear resistance of the slab without shear reinforcement

A. Latin lower case letters

$b_{\text {flex }}$ Width of each side of the punching cone

c Column width

$c_{1} \quad$ Nominal cover

d Effective depth of the slab

$d_{\text {res }}$ Depth of concrete above steel rebars

$f_{c}$ Compressive strength of concrete $f_{c t} \quad$ Tensile strength of concrete

fot.eff Effective tensile strength in concrete

$f_{s} \quad$ Stress in steel rebar

$f_{s h} \quad$ Stress at strain hardening

$f_{y} \quad$ Yield stress

$h \quad$ Slab overall depth

$l \quad$ Exposed length of reinforcement due to local damage progression

$n \quad$ Number of reinforcement bars

$n_{b r e a k}$ Total number of activated flexural reinforcement contributing to the post-punching resistance

$p_{\mathrm{i}} \quad$ Distance of progression of breakage of punching shear cone towards column

$q_{\mathrm{i}} \quad$ Distance of progression of spalling (or breakage) of concrete in slab away from the column

$s \quad$ Reinforcement bar spacing

$w$ Displacement

B. Greek lower case letters

$\gamma \quad$ Inclination of the concrete breakage cone with the horizontal

$\delta_{W} \quad$ Increment in slab displacement

$\varepsilon_{g} \quad$ Strain in steel rebar

$\varepsilon_{g h} \quad$ Strain at onset of strain hardening

$\varepsilon_{\text {gu }} \quad$ Strain at peak stress

$\varepsilon_{y} \quad$ Yield strain

$\theta$ Angle of inclination of punching shear cone with the horizontal

$\phi \quad$ Diameter of reinforcing steel bar

$\psi_{\text {flex }}$ Maximum rotation of rebar during flexural phase of post-punching shear response

$\psi_{\text {mem }}$ Steel rebar rotation at membrane phase of post-punching

Ulaeto, Nsikak William Department of Building, University of Uyo, Nigeria. BSc. Building (University of Uyo), MSc. Structural Engineering (University of Surrey), PhD Civil and Environmental Engineering (University of Surrey). Member Nigerian Institute of Building, Fellow Higher Education Academic (United Kingdom). Specialization: Materials and Building Structural Systems. 